http://dx.doi.org/10.36298/gerais2021 14e15805

\title{
Família, gênero e jornada de trabalho: uma revisão sistemática de literatura ${ }^{1}$
}

\section{Family, gender and work hours: a systematic review of the literature}

\author{
Meiridiane Domingues de Deus (orcid.org/0000-0002-9322-0162)2 \\ Mariana Effting de Sousa Schmitz (orcid.org/0000-0002-9931-790X)³ \\ Mauro Luís Vieira (orcid.org/0000-0003-0541-4133)4
}

\begin{abstract}
Resumo
Este estudo teve como objetivo investigar as produções científicas internacionais que relacionam as temáticas família, gênero e jornada de trabalho publicadas no período de 2012 a 2016. Realizou-se uma busca sistemática nas bases de dados SciELO, Lilacs, APA PsycNet, Scopus e Web of Science, por meio dos descritores family, gender e work hours e seus correspondentes em espanhol e português. Selecionaram-se 12 estudos, os quais integraram a amostra final desta revisão sistemática. Constatou-se que as mães são as principais responsáveis pelas atividades do lar e cuidados das crianças, o que evidencia a desigualdade de gênero nas atribuições de pais e mães no ambiente familiar. Destaca-se que a jornada de trabalho tem implicações no desempenho das funções parentais, em relação à saúde mental e física dos pais e mães, diminuição dos momentos de lazer e menor qualidade de tempo na assistência e cuidado das crianças.
\end{abstract}

Palavras-chave: Família. Gênero. Jornada de trabalho. Revisão sistemática.

\footnotetext{
Abstract

This study aimed to investigate the scientific production international that relate the themes family, gender and work hours published during the period of 2012 to 2016. A systematic search was conducted in the databases SciELO, Lilacs, APA PsycNet, Scopus and Web of Science through the descriptors family, gender, and work hours and their

1 O presente trabalho foi realizado com apoio da Coordenação de Aperfeiçoamento de Pessoal de Nível Superior Brasil (Capes) - Código de Financiamento 001.

${ }^{2}$ Universidade Federal de Santa Catarina, Florianópolis, Brasil. E-mail: meiridomingues@hotmail.com.

${ }^{3}$ Universidade Federal de Santa Catarina, Florianópolis, Brasil. E-mail: efftingmariana@gmail.com.

${ }^{4}$ Universidade Federal de Santa Catarina, Florianópolis, Brasil. E-mail: maurolvieira@gmail.com.
} 
correspondents in Spanish and Portuguese. There were selected 12 studies, which integrated the final sample of this systematic review. It was found that mothers are primarily responsible for the household activities and care of children, which evidences the gender inequality in the roles of fathers and mothers in the family environment. It is noteworthy that the work hours have implications in the performance of parental functions, in relation to the mental and physical health of the parents, decreased leisure time and lower quality of time in the assistance and care of children.

Keywords: Family. Gender. Work hours. Systematic review.

A família é o ambiente de desenvolvimento humano responsável pelas condições necessárias à sobrevivência, proteção, desenvolvimento social, cognitivo e afetivo do ser humano (Dessen \& Polonia, 2007). A definição de família na contemporaneidade considera os laços consanguíneos e grau de parentesco, assim como os vínculos afetivos, a intimidade e a proximidade entre as pessoas (Dessen, 2010). Destarte, o conceito de família foi ampliado a fim de englobar a diversidade de espectros e arranjos relacionais presentes na complexidade das famílias contemporâneas (Walsh, 2016).

As mudanças nas concepções, configurações e dinâmicas da família possibilitaram a expansão de padrões relacionais e papéis de gênero nesse contexto (Walsh, 2016). A inserção das mulheres no mercado de trabalho favoreceu modificações no ambiente familiar, bem como nos papéis desempenhados por pais e mães. Nos períodos anteriores à década de 1970, no Brasil, era evidente a divisão das tarefas por gênero na família: à mulher cabia as atividades do lar e o cuidado dos filhos, enquanto os homens eram responsáveis pelo provimento financeiro e familiar, por meio do trabalho (Aguiar, 2016). O conceito de gênero aqui utilizado refere-se às características e aos comportamentos socialmente designados aos homens e às mulheres em diferentes contextos sociais (Mahoney \& Knudson-Martin, 2009).

Na sociedade contemporânea, homens e mulheres vivenciam múltiplas funções, como a partilha de tarefas domésticas, o cuidado com os filhos e a administração das questões relativas ao trabalho (Santos, 2016). No entanto, a maior sobrecarga ainda está atrelada às mulheres, as quais, embora estejam inseridas no mercado de trabalho e com isso possam 
acessar maior autonomia e mudança de posição social, não têm a garantia de redução das responsabilidades vinculadas ao lar e aos filhos e têm condições de trabalho desiguais, quando comparadas aos homens (Hirata \& Kergoat, 2007). Além disso, lidam com o desafio de administrar uma dupla ou tripla jornada de trabalho.

Nesse contexto relacionado ao trabalho, salienta-se a jornada de trabalho dos pais e mães como aspecto importante a ser estudado, de modo a possibilitar o conhecimento das suas implicações no desempenho dos papéis parentais. A jornada de trabalho refere-se ao tempo de prestação de serviço ou disponibilidade do empregado ao empregador (Consolidação das Leis Trabalhistas [CLT], 2017) e constitui-se como um indicador da qualidade do emprego, regulação e proteção dos aspectos relacionados às condições de trabalho (Gama, 2014).

A regulamentação da jornada de trabalho foi ressaltada na constituição da Organização Internacional do Trabalho no ano de 1919. Nesse mesmo ano, na I Conferência Internacional do Trabalho, implantou-se a definição de oito horas diárias e 48 horas/semana como jornada de trabalho (Dedecca, Ribeiro \& Ishii, 2009). A Constituição Federal Brasileira (CF), no art. $7^{\circ}$, instituiu a jornada de trabalho remunerado com duração de oito horas diárias e 44 horas semanais (CF, 1988).

As questões relativas ao trabalho e à família já eram preocupações da Organização Internacional do Trabalho na década de 1960. Nessa perspectiva, o tempo configura-se como elo entre o trabalho e a família, visto que a carga horária despendida nesses espaços tem impacto tanto nas atribuições laborais como nas atividades ligadas à família e ao lar (Araújo, 2017). Assim, os estudos sobre o uso do tempo são importantes para a compreensão das desigualdades de gênero, entendimento da administração das horas relativas ao trabalho remunerado e não remunerado, além da investigação da injusta alocação das atribuições relacionadas ao trabalho doméstico e de cuidado por homens e mulheres que acontecem no cenário mundial. Entre as instituições que realizaram estudos sobre o uso do tempo, destacase o Comitê Técnico de Estudos de Gênero e Uso do Tempo (CGUT), formado por membros do Instituto Brasileiro de Geografia e Estatística (IBGE), Instituto de Pesquisa Econômica Aplicada 
(Ipea), Secretaria de Políticas para as Mulheres (SPM), Organização Internacional do Trabalho (OIT) e da ONU Mulheres - responsável pelo empoderamento feminino (Fontoura \& Araújo, 2016).

No Brasil, a partir do ano de 2000, a Pesquisa Nacional por Amostra de Domicílios (PNAD) e o IBGE realizaram coletas das informações sobre o tempo gasto no trajeto casa e trabalho, tempo despendido no trabalho remunerado e nas atividades domésticas. Também foram realizadas pela PNAD, pesquisas sobre a jornada de trabalho total relacionada ao mercado de trabalho e ao trabalho doméstico - afazeres domésticos (Dedecca et al., 2009). Em 2009, foi realizada uma pesquisa piloto sob a coordenação do IBGE, em que o foco principal foi a aplicação de uma metodologia baseada no registro de diários para compreender as disparidades de gênero relacionadas à família e ao trabalho (Araújo, 2016). Esses dados são importantes para tornar visíveis as disparidades de gênero tanto em relação à jornada de trabalho remunerado quanto relacionadas aos afazeres domésticos.

A jornada total das mulheres no contexto brasileiro, no ano de 2015 , foi de 55,1 horas/semana, enquanto a dos homens, 50,5 horas/semana (IBGE, 2015). Destaca-se a desigualdade nas jornadas de trabalho entre homens e mulheres, sobretudo mulheres de baixa renda, negras, pardas e indígenas, que têm maior jornada de trabalho total em relação às mulheres brancas e aos homens (Dedecca et al., 2009).

Por meio da Convenção n. 156, a OIT ressalta a importância da igualdade de oportunidades, tratamento sem discriminação e de forma que seja possível a conciliação das duas esferas, trabalho e família, para homens e mulheres (Meireles, 2016). Tal convenção reconhece a relevância de políticas nacionais voltadas para os problemas e aspectos relacionados ao trabalho e à família para trabalhadores(as). A Organização Internacional do Trabalho (2009) destaca que a conciliação entre trabalho e família deve ser considerada como corresponsabilidade social, em que implica responsabilização dos Estados, do mercado, da sociedade, dos homens e das mulheres. Assim, de acordo com a OIT, os trabalhadores(as) deveriam ter um suporte organizacional que garantisse o atendimento às demandas familiares 
(Meireles, 2016). Países da América do Sul, como Chile, Argentina, Paraguai, Uruguai, Bolívia, Venezuela e Peru ratificaram a Convenção n. 156, o que não é o caso do Brasil, resultando em prejuízo a todas as pessoas inseridas no mercado de trabalho (Meireles, 2016).

A família e o trabalho constituem-se como ambientes que possibilitam a (com) vivência de indivíduos, de modo a permitir produções e reproduções da vida social (Araújo, 2016). Esses espaços são considerados domínios interdependentes, ou seja, um afeta e é influenciado pelas características do outro (Araújo, 2017; Matias \& Fontaine, 2012) - ambos são áreas centrais na vida das pessoas. Para este estudo, será adotada a perspectiva do conflito entre trabalho e família.

O conflito trabalho-família se origina das demandas e pressões existentes em ambas as áreas. Assim sendo, Oliveira, Cavazotte e Paciello (2013) destacam que o desequilíbrio das responsabilidades nessas áreas pode contribuir para o surgimento de problemas relativos a aspectos físicos e psicológicos, como estresse, depressão, transtorno de humor, hipertensão; implicações nas atitudes e comportamentos dos (as) trabalhadores (as), por exemplo, absenteísmo, insatisfação no trabalho, redução no rendimento e comprometimento; e impactos sobre a satisfação no ambiente familiar, como falta de tempo para interações familiares. Essas questões são importantes de serem analisadas, principalmente com relação aos papéis e responsabilidades de pais e mães no contexto familiar. É necessária a conciliação das questões relativas aos domínios trabalho e família por pais e mães, mesmo que tenham intensas demandas familiares e profissionais, como também vida conjugal e cuidado com os filhos (Souza \& Moreira, 2016).

A compreensão das dinâmicas familiares e suas articulações com as questões de gênero e trabalho contribui para o conhecimento das implicações dos efeitos das articulações entre esses domínios, principalmente os relativos à jornada de trabalho. Assim, este estudo tem como objetivo investigar as produções científicas que relacionam a temática família, gênero e jornada de trabalho publicadas no período de 2012 a 2016. A escolha dessa delimitação de 
tempo ocorreu pela necessidade do acesso a estudos científicos atualizados em relação aos temas destacados.

\section{Método}

No mês de agosto de 2017, foi realizada uma busca sistemática na Biblioteca Virtual em Saúde (BVS Psi Brasil), sendo selecionadas as bases de dados Scientific Electronic Library Online (SciELO) e Literatura Latino Americana e do Caribe em Ciências da Saúde (Lilacs), por meio do Portal Periódicos Capes: APA PsycNet, Scopus e Web of Science. Os descritores utilizados foram family, gender e work hours e seus correspondentes em espanhol e português. Os dois primeiros descritores foram selecionados de acordo com a terminologia Psi, já o termo work hours não se encontra indexado ao vocabulário de termos em Psicologia, mas está cadastrado nos Descritores em Ciência da Saúde (DeCS). Foi utilizada uma equação de busca com a utilização do operador booleano AND. Family AND gender AND work hours.

A busca dos artigos científicos obedeceu aos seguintes critérios de inclusão: (i) acesso aos resumos nos idiomas português, espanhol e inglês; (ii) periódicos com textos completos disponíveis; (iii) publicação no período de 2012 a 2016; (iv) indexação em periódico científico; (v) ser um artigo empírico; (vi) relacionar os temas família, gênero e jornada de trabalho; e (vii) ter pais e mães como participantes das pesquisas. Já os critérios de exclusão foram: (i) texto de livros, congressos (resumos, trabalhos, conferências), jornais e revistas não científicas, teses e dissertações; e (ii) artigos científicos não disponíveis (pagos e/ou com acesso restrito).

Foram encontrados 548 artigos científicos. Desse total, foram removidos os artigos duplicados e aqueles que não se relacionavam à proposta deste estudo (373). Assim, foram selecionados 175 artigos científicos nacionais e internacionais. Posteriormente, foram lidos os títulos e os resumos por dois juízes independentes, que avaliaram e selecionaram os estudos, tendo como referência o objetivo e os critérios de inclusão propostos nesta revisão. Nesse procedimento, foram retirados 144 artigos, em função de não estarem relacionados aos 
critérios de inclusão. Esses artigos tinham como características: a) participantes das pesquisas: somente as mães $(n=40)$, somente os pais $(n=11)$; outros familiares $(n=1)$; b) temáticas abordadas: conflito trabalho-família sem relação com as funções parentais $(n=13)$, diferenças de gênero, mas não se relacionavam com questões referentes às figuras parentais $(n=14)$, equilíbrio família-trabalho $(n=4)$, atividades laborais e satisfação no trabalho $(n=12)$, saúde e trabalho $(n=11)$, aspectos relacionados à profissão $(n=4)$, alimentação $(n=4)$, satisfação no relacionamento familiar $(n=6)$, comportamento das crianças $(n=5)$, cuidados com idosos $(n=2)$, homoparentalidade $(n=3)$, esporte $(n=3)$, migração $(n=1)$. Além disso, havia 10 artigos indisponíveis para acesso livre.

Após a seleção dos artigos conforme os objetivos e os critérios de inclusão deste estudo, foi realizada a leitura na íntegra de 31 estudos nacionais e internacionais a fim de viabilizar a sua inclusão nesta revisão. Não foram selecionados artigos nacionais em função das especificidades do critério de inclusão, como a necessidade de que os participantes fossem as duas figuras parentais, o pai e a mãe. O artigo nacional encontrado na busca não tem pais e mães como participantes da pesquisa, embora tenha como objetivo mapear os padrões de relações e questões de gênero, com foco na conjugalidade e parentalidade, vida profissional, dinâmica de trabalho doméstico e remunerado (Araújo \& Veiga, 2015). Assim, foram selecionados 12 artigos científicos internacionais, que foram lidos e analisados. No Quadro 1, destaca-se a autoria e o ano da publicação, país de origem, participantes, método e desenho do estudo. Os resultados dos artigos foram organizados em categorias. A Figura 1 descreve o percurso metodológico da seleção. 
Figura 1. Percurso metodológico da seleção dos artigos

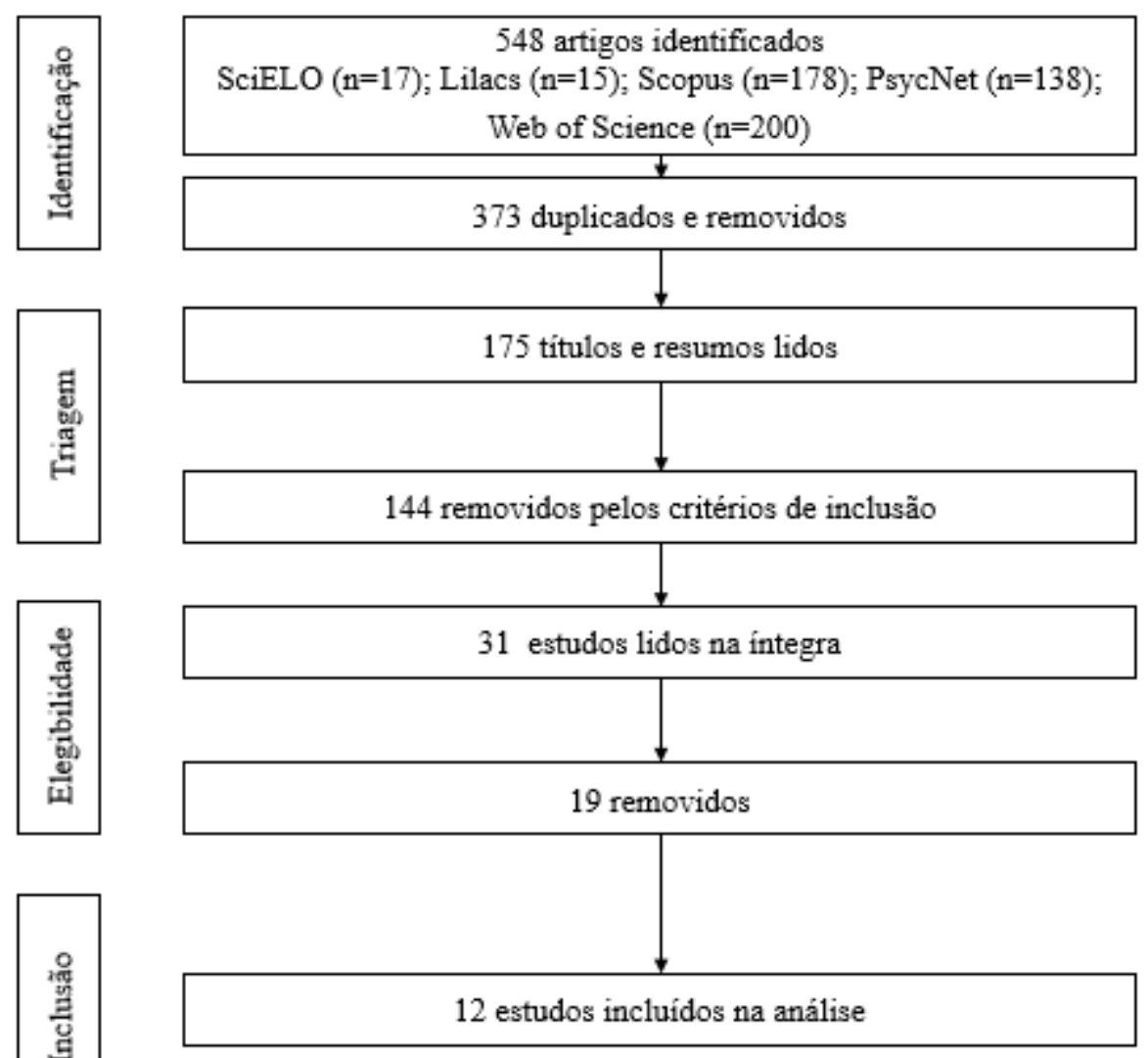

Fonte: Elaborada pelos autores.

Após a leitura desses artigos, foi realizada a análise de conteúdo, conforme os critérios de Bardin (2016). Assim, elencaram-se três categorias: implicações da jornada de trabalho para os pais e mães; influências da jornada de trabalho dos pais e das mães no desenvolvimento infantil; e aspectos do conflito entre trabalho e família.

\section{Resultados}


O Quadro 1 destaca as características dos estudos incluídos nesta revisão. Foram selecionados 12 artigos científicos que tinham pais e mães como participantes.

Quadro 1. Caracterização dos estudos incluídos na revisão

\begin{tabular}{|c|c|c|c|c|}
\hline Autoria e ano & País & Participantes & Método & $\begin{array}{c}\text { Desenho do } \\
\text { estudo }\end{array}$ \\
\hline $\begin{array}{l}\text { Hostetler, } \\
\text { Desrochers, Kopko e } \\
\text { Moen (2012) }\end{array}$ & $\begin{array}{l}\text { Estados } \\
\text { Unidos }\end{array}$ & $\begin{array}{c}520 \text { pais e mães } \\
\text { (260 casais) }\end{array}$ & Quantitativo & Transversal \\
\hline Minotte (2012) & $\begin{array}{l}\text { Estados } \\
\text { Unidos }\end{array}$ & $\begin{array}{c}1.325 \text { pais e } \\
\text { mães }\end{array}$ & Quantitativo & Transversal \\
\hline Taht e Mills (2012) & Holanda & $\begin{array}{l}1.266 \text { casais } \\
\text { (pais e mães) }\end{array}$ & Misto & Transversal \\
\hline $\begin{array}{l}\text { Farias, Soto e } \\
\text { Figueroa (2013) }\end{array}$ & Chile & $\begin{array}{c}93 \text { pais e } 131 \\
\text { mães }\end{array}$ & Quantitativo & Transversal \\
\hline $\begin{array}{l}\text { Johnson, Li, Kendall, } \\
\text { Strazdins e Jacobs } \\
\text { (2013) }\end{array}$ & Austrália & $\begin{array}{l}\text { Pais e mães de } \\
\text { crianças com } \\
\text { idade de } 5,8 \text { e } \\
10 \text { anos de } \\
\text { idade }\end{array}$ & Quantitativo & Transversal \\
\hline Kanji (2013) & $\begin{array}{l}\text { Reino Unido, } \\
\text { País de Gales, } \\
\text { Inglaterra, } \\
\text { Escócia e } \\
\text { Irlanda do }\end{array}$ & 15.335 casais & Quantitativo & Longitudinal \\
\hline
\end{tabular}




\begin{tabular}{|c|c|c|c|c|}
\hline & Norte & & & \\
\hline Offer (2014) & $\begin{array}{l}\text { Estados } \\
\text { Unidos }\end{array}$ & $\begin{array}{l}500 \text { famílias } \\
\text { (pais e mães) }\end{array}$ & Quantitativo & Transversal \\
\hline Yavorsky, Dush e & Estados & 364 casais (pais & Quantitativo & Longitudinal \\
\hline $\begin{array}{l}\text { Schoppe-Sullivan } \\
\text { (2015) }\end{array}$ & Unidos & e mães) & & \\
\hline $\begin{array}{l}\text { Gracia e Kalmijn } \\
\text { (2016) }\end{array}$ & Espanha & $\begin{array}{l}1.416 \text { casais } \\
\text { (pais e mães) }\end{array}$ & Quantitativo & Transversal \\
\hline $\begin{array}{l}\text { Roeters e Gracia } \\
(2016)\end{array}$ & $\begin{array}{l}\text { Estados } \\
\text { Unidos }\end{array}$ & $\begin{array}{c}1.699 \text { pais e } \\
\text { mães }\end{array}$ & Misto & Transversal \\
\hline Cooklin et al. (2016) & Austrália & $\begin{array}{l}2.693 \text { mães e } \\
3.460 \text { pais }\end{array}$ & Misto & Longitudinal \\
\hline $\begin{array}{l}\text { Lozano, Hamplová e } \\
\text { Le Bourdais (2016) }\end{array}$ & Canadá & $\begin{array}{c}1.932 \text { pais e } \\
\text { mães }\end{array}$ & Quantitativo & Transversal \\
\hline
\end{tabular}

Fonte: Elaborado pelos autores.

O método mais utilizado nos estudos foi o levantamento de dados (entrevistas e questionários), sendo em alguns casos combinado com aplicação de escalas, uso de diário para registro de tempo e observações das interações familiares. O tipo de análise dos dados coletados foi em sua maioria quantitativa, sendo representada por nove estudos selecionados, enquanto três utilizaram a análise qualitativa e quantitativa. Os resultados dos estudos foram organizados em três categorias, expostas a seguir.

Implicações da jornada de trabalho para os pais e as mães 
Esta categoria apresenta os resultados referentes a sete estudos. Os temas dos artigos selecionados referiram-se a aspectos como: uso do tempo, níveis de estresse, jornada e turno de trabalho das figuras parentais, atividades domésticas, lazer e relacionamento do casal.

Os estudos selecionados, em sua maioria, apresentam as mães como as figuras parentais que realizam múltiplas tarefas relativas ao cuidado com os(as) filhos(as) e são responsáveis por mais atividades domésticas, em comparação com os pais. Exemplo disso é o estudo realizado por Offer (2014), que constatou que as mães passam o dobro do tempo no desempenho de atividades de cuidados infantis, em relação aos pais. Consequentemente, as mães experimentam maiores níveis de estresse, em comparação aos pais (Offer, 2014; Roeters \& Gracia, 2016). Dessa forma, sentem-se mais apressadas em relação à administração das atividades e demandas do tempo, principalmente quando o seu companheiro tem uma longa jornada de trabalho (maior que 50 horas/semana), o que contribui para o aumento dos níveis de estresse.

A jornada de trabalho de homens e mulheres tem implicações no desempenho das suas funções parentais e, também, em períodos específicos vivenciados pela família. Nessa perspectiva, o estudo realizado por Yavorsky, Dush e Schoppe-Sullivan (2015), com casais que experienciaram a transição para a parentalidade, constatou que as mães, além de lidar com as demandas do trabalho remunerado, realizavam mais atividades de cuidados infantis do que os pais. Esse aspecto contribui para uma sobrecarga de horário maior, surgimento de limitações físicas e fadiga.

As mulheres realizam mais atividades de cuidado e trabalho doméstico que os homens (Lozano, Hamplová \& Le Bourdais, 2016) e, nesse contexto, a possibilidade de flexibilização dos horários de trabalho pode favorecê-las no desempenho das suas atividades familiares e laborais. Ressalta-se a necessidade de uma rede de apoio dos familiares e vizinhos (Hostetler, Desrochers, Kopko \& Moen, 2012) e contratação de serviços pagos e/ou o auxílio dos companheiros na realização das atividades domésticas a fim de contribuir para a redução da sobrecarga diária feminina (Lozano et al., 2016). 
Aspectos relacionados ao trabalho, como o turno e a jornada de trabalho de pais e mães, têm implicações no desempenho das atividades relacionadas ao meio familiar. O estudo realizado por Gracia e Kalmijn (2016) apontou que os pais se envolvem mais nas atividades relativas aos filhos quando as suas companheiras trabalham no turno da noite. Já em relação à jornada de trabalho, o aumento das horas de trabalho remunerado dos pais contribui para a diminuição da disposição para as atividades de cuidado das crianças (Roeters \& Gracia, 2016).

Em relação ao lazer, os pais costumam realizar mais ativamente atividades fora do contexto familiar, quando comparados às mães (Gracia \& Kalmijn, 2016). Já as figuras maternas estão mais propensas a levar consigo seus filhos quando se envolvem em atividades fora do ambiente familiar (Offer, 2014). Levando-se isso em consideração, a idade dos filhos é uma questão importante, visto que mães que têm filhos adolescentes podem experimentar maiores níveis de estresse que as que têm filhos pequenos (Lozano et al., 2016).

Aspectos relacionados ao trabalho, como a renda e o compartilhamento das atividades diárias, podem ter influência no relacionamento do casal. A renda é um aspecto relevante a ser considerado, visto que casais que têm igualdade de renda entre os membros trabalham menos horas do que os que têm renda desigual (Kanji, 2013). Além disso, o compartilhamento de atividades diárias é algo importante, e ter um(a) companheiro(a) que participe das demandas familiares e laborais contribui positivamente para a redução dos níveis de estresse para pais e mães (Roeters \& Gracia, 2016).

\section{Influências da jornada de trabalho dos pais e das mães no desenvolvimento infantil}

Essa categoria aborda os resultados de dois artigos, que apresentam os seguintes aspectos: problemas comportamentais das crianças e influência do turno e horário de trabalho das figuras parentais na participação das atividades dos filhos.

A jornada de trabalho dos pais e das mães pode ter influência no comportamento dos

filhos. O estudo realizado por Jonhson, Li, Kendall, Strazdins e Jocobs (2013) constatou que a 
jornada de trabalho das mães não tem influência nos problemas comportamentais das crianças. Em relação aos pais, quanto maior a sua jornada de trabalho, maior a possibilidade de meninos expressarem comportamentos externalizantes. Exemplo disso foram os filhos de pais com jornada de trabalho longa (maior do que 55 horas/semana), que apresentaram maiores níveis de comportamentos externalizantes. Os autores problematizam a ausência materna como fonte de impacto negativo para o desenvolvimento das crianças e, além disso, atentam para as implicações que o afastamento do pai pode trazer para os filhos.

O turno e os horários em que pais e mães trabalham influenciam a participação das figuras parentais nas atividades dos(as) filhos(as). O turno e o trabalho em horários não padronizados (turno da noite e nos fins de semana) contribuem para a maior participação dos pais nas atividades das crianças, como levá-las à escola ou à creche e realização de cuidados em caso de doença. O trabalho noturno constitui um aspecto negativo que pode influenciar a interação entre pai e filhos, visto que as figuras parentais podem apresentar cansaço e irritabilidade, o que desfavorece o convívio e participação na vida dos filhos (Taht \& Mills, 2012), porém, trabalhar nesses horários diferenciados possibilita a criação de estratégias de suporte e envolvimento dos pais e mães com as crianças.

\section{Aspectos do conflito entre trabalho e família}

Esta categoria é composta de três estudos e aborda temas como a saúde mental das figuras parentais e conflito trabalho-família.

Alguns aspectos contribuem significativamente para a menor saúde mental das figuras parentais, como as condições e o histórico de saúde, doenças crônicas, baixa qualidade na relação com os(as) parceiros(as), baixa renda e insatisfação no trabalho. Para os pais (homens), a redução da saúde mental está vinculada à idade inferior a 34 anos e longas jornadas de trabalho - 40 a 50 horas/semanais ou mais (Cooklin et al., 2016). 
Para as figuras paternas, o conflito trabalho-família está relacionado com a baixa qualidade do ambiente de trabalho, longa jornada de trabalho e profissão de reconhecimento social (alto status). Para as mães, o conflito trabalho-família está associado a profissões com alta ou baixa qualificação, longa jornada de trabalho e insegurança no emprego (Cooklin et al., 2016). De acordo com Farias, Soto e Figueroa (2013), as atividades das mulheres no ambiente familiar independem das suas jornadas de trabalho, e esse aspecto não se relaciona à imagem que têm sobre si como boas mães. Em famílias nas quais as mães são as principais responsáveis pelos filhos, o conflito trabalho-família tem maior expressão do que nos lares em que os pais são os principais provedores. No entanto, quando pais e mães são os únicos responsáveis pelos filhos, geralmente podem contar com uma importante rede de apoio dos familiares, no caso de problemas financeiros e conflito trabalho-família (Minotte, 2012).

\section{Discussão}

Os estudos selecionados para esta revisão foram desenvolvidos em países da América Central, América do Sul, Europa e Oceania, dado que vai ao encontro da perspectiva dos estudos sobre o uso do tempo e gênero que vêm sendo realizados em países como Estados Unidos, Austrália, Canadá, Chile e outros países da América Latina e Europa (Fontoura \& Araújo, 2016). Os estudos sobre o uso do tempo contribuem para o entendimento das desigualdades e demandas de gênero, compreensão das questões relativas ao tempo gasto no trabalho remunerado e não remunerado. Ademais, favorece a percepção da injusta distribuição das tarefas referentes ao trabalho doméstico e de cuidado realizado por homens e mulheres.

Em geral, as pesquisas relativas ao uso do tempo e gênero são quantitativas, longitudinais e utilizam o diário como técnica de coleta de dados (Barajas, 2016; Fontoura \& Araújo, 2016). Um exemplo disso foi o estudo longitudinal realizado por Kitterod e Ronsen (2016) - com pais noruegueses, com objetivo de investigar a alocação do tempo das atividades de trabalho familiar e práticas de paternidade -, que utilizou o diário como técnica de coleta de 
dados e, posteriormente, foram realizadas entrevistas a fim de aprofundar as informações. Esse dado vai ao encontro dos estudos analisados nesta revisão, pois o diário foi utilizado para o registro das atividades parentais e, em alguns casos, essa técnica foi combinada a entrevistas, questionários e aplicação de escalas. Destaca-se o uso do diário como importante instrumento de coleta de dados para o registro das atividades diárias dos pais e mães, bem como possibilitar a reflexão relativa às disparidades que envolvem as atividades realizadas por homens e mulheres (Fontoura \& Araújo, 2016).

As desigualdades de papéis sociais e atividades desempenhadas por homens e mulheres foi um aspecto evidenciado nos resultados desta revisão (Offer, 2014; Roeters \& Gracia, 2016; Yavorsky et al., 2015). Como consequência dessa disparidade entre a distribuição das atividades, no contexto da parentalidade, as mães experienciam maiores níveis de estresse pelo acúmulo de funções no trabalho, em casa e na família, em comparação com os pais. Além disso, têm maiores jornada de trabalho total, em relação aos pais (Gama, 2014).

O estudo realizado por Yavorsky et al. (2015) constatou variações na jornada de trabalho semanal relacionadas ao gênero, visto que homens têm maior jornada de trabalho remunerado semanal do que as mulheres. Dado que se comprova nas pesquisas realizadas pelo IBGE no Brasil com pessoas com idade de 16 anos ou mais, em que foi constatado que os homens têm uma jornada de trabalho total semanal de 40,8 e as mulheres, 34,9 (IBGE, 2015). Destaca-se o reforço aos papéis tradicionais de gênero, em que os homens são os provedores familiares e as mulheres responsáveis pelas atividades de cuidado. Entretanto, na realidade, a jornada de trabalho total das mulheres excede a dos homens, em função das suas responsabilidades com as atividades domésticas e cuidados familiares (Dedecca et al., 2009).

Questões relativas ao trabalho (como jornada de trabalho, turno e sobrecarga de atividades) e às desigualdades no desempenho das atividades do trabalho remunerado podem trazer consequências para a participação das mães e pais no ambiente familiar. Exemplo disso é o turno em que os pais e mães trabalham. O exercício das atividades laborais no período noturno e fins de semana pode estimular os pais a combinar a realização das atividades de 
assistência infantil e o desempenho das funções laborais (Begall, Mills \& Ganzeboom, 2014), tal como aponta o estudo de Gracia e Kalmijn (2016) e Taht e Mills (2012). Em contrapartida, o trabalho em horários diferenciados tende a favorecer o surgimento de maiores níveis de problemas emocionais e comportamentais na criança e níveis elevados de estresse, depressão e culpa nas figuras parentais (Han, Miller \& Walfogel, 2010).

Outra questão refere-se ao período específico vivenciado pelo casal. O estudo realizado por Yavorsky et al. (2015), com casais que vivenciam o período de transição para a parentalidade, destacou que as mães tendem a lidar mais com as questões laborais e os cuidados infantis, em relação aos pais, o que contribui para sua sobrecarga física. A maternidade ainda é um dos fatores que mais interferem no trabalho feminino, principalmente quando os filhos são pequenos e os rendimentos obtidos são insuficientes para cobrir os custos com formas remuneradas de cuidado (Gama, 2014). Essa questão vai ao encontro dos achados de Yavorsky et al. (2015) e Roeters e Gracia (2016). Porém, não é somente nesse período que os pais e mães podem experimentar os efeitos do trabalho remunerado e da demanda de cuidados, mas, também, nas fases escolar, pré-escolar e na adolescência dos(as) filhos(as), como salientado no estudo realizado por Lozano et al. (2016).

Aspectos relacionados à renda são importantes no estudo de gênero e família, visto que evidenciam as desigualdades entre homens e mulheres. Quando se relaciona aos aspectos da conjugalidade, pode-se verificar que casais com alta renda têm maiores taxas de ocupação no mercado de trabalho e menores jornadas de trabalho, em relação aos que têm baixa renda (Gama, 2014). O estudo de Kanji (2013) constatou que casais com alta renda têm menores jornada de trabalho, no entanto, essa realidade se modifica quando se analisa famílias em situação de pobreza. Nestas, as mulheres com filhos pequenos têm dificuldades de inserção no mercado de trabalho, o que causa impacto na geração de renda familiar (Gama, 2014), o que contribui para a desigualdade de gênero e disparidade social entre as famílias.

Outra questão de grande importância, quando se estuda família, gênero e jornada de trabalho, refere-se ao trabalho de cuidado não remunerado ou doméstico. Dados do IBGE 
(2015) retratam a disparidade de gênero em relação aos afazeres domésticos entre pessoas com idade de 16 anos ou mais, as mulheres gastam cerca de 20,5 horas/semana, enquanto os homens, 10 horas/semana. Na maioria das vezes, as mulheres são as responsáveis pelas atividades domésticas (cozinhar, administrar e limpar a casa) e de cuidados na família (McGoldrick, 1995). Exemplo disso são os estudos realizados por Lozano et al. (2016) e Yavorsky et al. (2015), que demonstraram a maior participação feminina no que se refere às questões do lar. A mensuração do tempo dedicado ao trabalho do cuidado não remunerado implica dar visibilidade social para um conjunto de atividades, em grande parte exercida por mulheres (Gama, 2014). Isso implica em possibilitar elaboração de políticas públicas, bem como programas de saúde e de incentivo à igualdade de gênero. Além disso, reforça a necessidade de aumento do número de creches para as mães inseridas no mercado de trabalho.

As mães ainda são as principais provedoras dos cuidados relativos à família. Nesse contexto, a participação do companheiro, como apresentado nos estudos de Roeters \& Gracia (2016) e Offer (2014), possibilita a redução dos níveis de estresse materno. A pesquisa realizada por Minotte (2012) salienta a necessidade de uma rede de apoio a pais e mães em famílias monoparentais em situação de conflito entre trabalho e família. No entanto, destaca-se a delegação não remunerada das responsabilidades, principalmente em atividades de cuidado a outras mulheres, como mães, tias, filhas ou avós (Moser \& Dal Pra, 2016), o que também contribui para a sobrecarga feminina. Assim, faz-se necessário que o casal se responsabilize de forma equânime pelo cuidado dos filhos e das tarefas domésticas, de modo a não sobrecarregar as mulheres.

As mães tendem a passar mais tempo com os filhos do que os pais, mesmo quando exercem atividade em turno integral - manhã e tarde (Gauthier \& DeGusti, 2012). Considerando isso, os pais parecem estar em um período de transição na paternidade, no sentido de que suas atividades ainda contemplam atividades tradicionais (provisão econômica) e, junto disso, características de um pai moderno, mais participativo no ambiente familiar e na criação dos filhos (Bossardi, Gomes, Vieira \& Crepaldi, 2013). Isso possibilita a reflexão sobre as 
desigualdades de gênero nas atividades das figuras parentais, como também entender a sobrecarga das mães nas suas atividades diárias, que se dividem em atividades de administração do lar, atribuições profissionais e cuidados com a família.

A jornada de trabalho de pais e mães também tem influência no desenvolvimento infantil. O estudo realizado por Jonhson et al. (2013) enfatizou a influência da jornada de trabalho do pai no surgimento de problemas comportamentais em crianças, principalmente em meninos. A pesquisa realizada por Gomes, Bigras e Crepaldi (2013) ressalta que jornada de trabalho do pai interfere no envolvimento paterno. Esses autores destacam que o envolvimento do pai nas tarefas do lar e atividades de cuidados básicos com as crianças tem repercussões no desenvolvimento dos filhos, de modo a possibilitar o controle da agressividade infantil e, com isso, a redução de problemas externalizantes (impulsividade, agressividade, comportamentos desafiadores e antissociais).

O turno em que pais e mães trabalham influencia a participação das figuras parentais nas atividades dos(as) filhos(as). O estudo realizado por Taht e Mills (2012), com o objetivo de comparar as condições de trabalho, o bem-estar pessoal e o envolvimento parental entre pais dos turnos diurnos e noturno, aponta que o turno noturno pode influenciar negativamente na interação entre pais e filhos. Nessa perspectiva, a pesquisa realizada por Cia e Barham (2008), com 58 pais, sendo que 36 trabalham no período diurno e 22 no noturno, constatou que pais que desempenham suas atividades à noite sentiram-se insatisfeitos em relação à falta de tempo para interações familiares. Além disso, os pais que trabalhavam de dia tinham mais tempo de interação e envolvimento com os filhos do que aqueles que desempenham atividades no período noturno. Embora, muitas vezes, os pais não possam estar com seus filhos, não é somente a quantidade de tempo que importa, mas a qualidade das interações que realizam com as crianças.

As mudanças sociais, sobretudo a inserção feminina no mercado de trabalho, contribuíram de modo significativo para o aumento do conflito trabalho e família, visto que às mulheres era atribuído o papel de cuidadoras da família, enquanto aos homens cabia a provisão 
financeira. Quando as mulheres passaram a se inserir no mercado de trabalho, surgiu uma maior necessidade de os homens voltarem-se à família e suas demandas de cuidado.

O desequilíbrio e o surgimento do conflito entre trabalho e família se tornam evidentes quando não há delimitação de fronteiras entre essas duas esferas da vida de homens e mulheres. Assim, nessa perspectiva do conflito entre trabalho e família, pode haver efeitos significativos na saúde física e mental, principalmente para os pais e mães, tal como aponta o estudo realizado por Cooklin et al. (2016), em que as longas jornadas de trabalho estão relacionadas à redução da saúde mental dos pais. Esses autores ainda destacam que o conflito entre trabalho e família, tanto para os pais como para as mães, é influenciado pelas longas jornadas de trabalho. No entanto, especificamente para os pais (homens), esse conflito está relacionado à baixa qualidade no ambiente de trabalho e profissões de reconhecimento social; para as mães, associa-se à profissão, tanto de alta quanto de baixa qualificação, e à insegurança no trabalho. O estudo realizado por Farias, Soto \& Figueroa (2013) aponta que as famílias monoparentais, em que as mulheres são principais responsáveis, há uma tendência a maior conflito entre trabalho e famílias, em relação às que são chefiadas pelos pais. Assim, como salienta Minotte (2012), é importante que exista uma rede de apoio para esses (as) provedores (as).

A pressão do tempo e a tensão emocional são duas dimensões relacionadas ao gerenciamento das dificuldades entre as responsabilidades profissionais e familiares (Craig \& Mullan, 2010). As mulheres vivenciam uma sobrecarga e dificuldade de conciliar as demandas entre trabalho e família, sobretudo as que têm baixa renda (Gama, 2014; Moser \& Dal Pra, 2016). Esses fatores prejudicam as oportunidades de tempo de lazer dos pais e mães.

O tempo de lazer para pais e mães é um aspecto importante em relação à conciliação entre atribuições familiares e relativas ao trabalho. A alta sobrecarga e tempo de ocupação com o trabalho remunerado pode comprometer o tempo de lazer familiar e envolvimento no cuidado das crianças. Nos momentos destinados ao lazer, as mães tendem a levar consigo as crianças, tal como evidenciado no estudo de Offer (2014). Assim, destaca-se a dificuldade das mães em 
usufruir de momentos de lazer e das suas atribuições no ambiente familiar, algo que contribui para o conflito entre trabalho e família.

\section{Considerações finais}

Este estudo teve como objetivo investigar as produções científicas que relacionam a temática família, gênero e jornada de trabalho publicadas no período de 2012 a 2016. Constatou-se que as mães são as principais responsáveis pelas atividades do lar e cuidados das crianças, o que evidencia a desigualdade de gênero nas atribuições de pais e mães no ambiente familiar. Além disso, a jornada de trabalho tem implicações no desempenho das funções parentais, em relação à saúde mental e física dos pais e mães, diminuição dos momentos de lazer, como também menor qualidade de tempo na assistência às crianças. Salientam-se as implicações no desenvolvimento infantil, principalmente relativas a fatores comportamentais. A jornada de trabalho de pais e mães também pode favorecer o surgimento de conflito trabalhofamília.

Destaca-se a disparidade de tempo despendido pelas mães nos afazeres domésticos e atividades relativas ao cuidado da família e das crianças, em relação aos homens, embora atualmente alguns pais estejam mais envolvidos nas atividades relacionadas ao cuidado das crianças e atividades do lar.

Ressalta-se a necessidade de investigações aprofundadas, de modo a contribuir para o conhecimento das implicações da jornada de trabalho nas atribuições e funções parentais e no ambiente familiar, bem como no desenvolvimento infantil. Assim, reforça-se a relevância da realização de estudos quantitativos e qualitativos como forma de compreender as estratégias de cuidado e suporte que pais e mães utilizam no envolvimento e criação das crianças, o que pode subsidiar o planejamento e execução de intervenções e ações de promoção de saúde na família e de seus membros. Além disso, justifica-se a necessidade de maior investimento e 
disponibilidade de vagas em creches e instituições de ensino infantil, como forma de auxiliar pais e mães no equilíbrio entre trabalho e família.

Considera-se como limitação desse estudo a seleção de artigos internacionais, o que impossibilitou conhecer e compreender como essa temática está sendo discutida e analisada no cenário brasileiro. Foram lidos alguns artigos nacionais na seleção dos estudos, mas salienta-se que tinham como participantes somente uma das figuras parentais. É grande o número de artigos relacionados às temáticas trabalho e família que têm as mães como participantes das pesquisas. Entretanto, ainda é incipiente o número de produções relativas aos pais e mães em relação a essa temática. A contribuição deste estudo relaciona-se a visibilizar artigos científicos que integram pais e mães e a questão do conflito trabalho e família.

Sugere-se a realização de estudos aprofundados em diferentes contextos socioeconômicos e culturais, ressaltando que as desigualdades de gênero são expressivas quando se considera fatores como renda, raça e etnia, principalmente para as mulheres. Mesmo com os avanços nos direitos relacionados à inserção das mulheres no mercado de trabalho, quando se relaciona às funções parentais, as mães são as mais afetadas pela sobrecarga de responsabilidades, em decorrência da soma de atribuições profissionais e cuidados domésticos. Embora existam mudanças em relação à paternidade, espera-se que os homens possam estar mais envolvidos nas atividades relativas ao lar e ao cuidado com os filhos. Essas questões devem ser consideradas na realização de novas pesquisas relacionadas às temáticas trabalho e família.

Além disso, sugere-se a realização de estudos que considerem a diversidade de arranjos e relações familiares relacionados à influência das questões ligadas ao trabalho, como ocupações, turno, cargos, saúde do trabalho, desemprego e home office; parentalidade e coparentalidade. Em relação à família, salienta-se a relevância do legado cultural das famílias e fatores intergeracionais relacionados à temática família, gênero e jornada de trabalho. 


\section{Referências}

Aguiar, C. V. N. (2016). Interfaces entre o trabalho e a familia e os vínculos organizacionais: explorando a tríade família- trabalho-organização. Tese de doutorado, Instituto de Psicologia, Universidade Federal da Bahia, Salvador, Brasil. Recuperado de https://pospsi.ufba.br/sites/pospsi.ufba.br/files/carolina_villa_nova_tese.pdf.

Araújo, C. (2016). Apresentação. In N. Fontoura \& C. Araújo (Orgs.). Uso do tempo e gênero (pp.13-15). Rio de Janeiro: Uerj.

Araújo, A. A. (2017). Corresponsabilidade familiar e proteção do mercado de trabalho da mulher: o sistema internacional da OIT como fonte integrativa da garantia constitucional. Dissertação de mestrado, Universidade Federal do Rio Grande do Norte, Natal, Brasil. Recuperado de https://repositorio.ufrn.br/jspui/handle/123456789/23581.

Araújo, C., \& Veiga, A. (2015). Domesticidade, trabalho e satisfação pessoal: horas no trabalho doméstico e bem-estar no estado do Rio de Janeiro. Revista Brasileira de Ciência Política, 18, 179-209. doi: 10.1590/0103-335220151807.

Barajas, M. P. L. (2016). Avanços na América Latina na medição e valoração do trabalho não remunerado realizado por mulheres. In N. Fontoura \& C. Araújo. Uso do tempo e gênero (pp. $21-42$ ). Rio de Janeiro: Uerj.

Bardin, L. (2016). Análise de conteúdo. São Paulo: Edições 70.

Begall, K., Mills, M., \& Ganzeboom, H. B. G. (2014). Non-Standard Work Schedules and Childbearing in the Netherlands: A Mixed-Method Couple Analysis. Social Forces, 93(3), 1-32. doi: 10.1093/sf/sou 110. 
Bossardi, C. N., Gomes, L. B., Vieira, M. L., \& Crepaldi, M. A. (2013). Engajamento paterno no cuidado a crianças de 4 a 6 anos. Psicologia Argumento, 31(73), 237-246. Recuperado de https:/ / www.researchgate.net/publication / 321285928 Engajamento_paterno_no_cuidado _a_criancas_de_4_a_6_anos.

Cia, F., \& Barham, E. J. (2008). Trabalho noturno e o novo papel paterno: uma interface difícil. Estudos em Psicologia, 25(2), 211-222. doi: 10.1590/S0103-166X2008000200006.

Consolidação das leis do trabalho - CLT. (2017). CLT e normas correlatas. Brasília: Senado Federal, Coordenação de Edições Técnicas, 189 p.

Constituição da República Federativa do Brasil de 1988. (1988). Brasília, DF: Senado Federal: Centro Gráfico. 292 p.

Cooklin, A. R., Dinh, H., Strazdins, L., Westrupp, E., Leach, L. S., \& Nicholson, J. M. (2016). Change and Stability in Work-Family Conflict and Mother's and Fathers' Mental Health: Longitudinal Evidence from an Australian Cohort. Social Science \& Medicine, 155, 24-34. doi: $10.1016 /$ j.socscimed.2016.02.036.

Craig, L., \& Mullan, K. (2010). Parenthood, Gender and Work-Family Time in the United States, Australia, Italy, France, and Denmark. Journal of Marriage Family, 72(5), 1344-1361. doi: $10.1111 / \mathrm{j} .1741-3737.2010 .00769 . x$.

Dedecca, C. S., Ribeiro, C. S. M. F., \& Ishii, F. H. (2009). Gênero e jornada de trabalho: análise das relações entre mercado de trabalho e família. Revista Trabalho, Educação \& Saúde, 7(1), 65-90. doi: 10.1590/S1981-77462009000100004.

Dessen, M. A. (2010). Estudando a família em desenvolvimento: desafios conceituais e teórico. Psicologia: Ciência e Profissão, 30(n. esp.), 202-219. doi: 10.1590/S141498932010000500010. 
Dessen, M. A., \& Polonia, A. C. (2007). Família e escola como contextos de desenvolvimento humano. Paidéia, $\quad$ l7(36), 21-32. Recuperado de http://www.scielo.br/pdf/paideia/v17n36/v17n36a03.pdf.

Farias, A. O., Soto, D. R., \& Figueroa, A, J. (2013). Equilibio trabajo-familia: corresponsabilidad familiar y autoeficacia parental en trabajadores de una empresa chilena. Diversitas: $\begin{array}{llll}\text { Perspectivas em Psicología, } & \text { 9(1),55-64. } & \text { Recuperado de }\end{array}$ http:/ / www.redalyc.org/articulo.oa?id $=67926246008$.

Fontoura, N., \& Araújo, C. (Orgs). (2016). Uso do tempo e gênero. Rio de Janeiro: Uerj.

Gama, A. S. (2014). Trabalho, família e gênero: impactos dos direitos do trabalho e da Educação infantil (1 a ed.) São Paulo: Cortez.

Gauthier, A., \& DeGusti, B. (2012). The Time Allocation to Children by Parents in Europe. International Sociology, 27(6), 827-845. doi: $10.1177 / 0268580912443576$.

Gomes, L. B., Bigras, M., \& Crepaldi, M. A. (2013). O engajamento paterno como fator de regulação da agressividade em pré-escolares. Paidéia, 23(54), 21-29. doi: $10.1590 / 1982-43272354201304$.

Gracia, P., \& Kalmijn, M. (2016). Parent's Family Time and Work Schedules: the Split-Shift Schedules in Spain. Journal of Marriage and Family, 78(2), 401-415. doi: $10.1111 /$ jomf.12270.

Han, W. J., Miller, D. P., \& Waldfogel, J. (2010). Parental Work Schedules and Adolescent Risky Behaviors. Developmental Psychology, 46(5), 1245-1267. Retrieved from https://www.ncbi.nlm.nih.gov/pmc/articles/PMC3742548/. 
Hirata, H., \& Kergoat, D. (2007). Novas configurações da divisão sexual do trabalho. Cadernos de Pesquisa, 37(132), 595-609. Recuperado de http://scielo.br/pdf/cp/v37n132/a0537132.

Hostetler, A. J., Desrochers, S., Kopko, K., \& Moen, P. (2012). Marital and Family Satisfaction as a Function of Work-Family Demands and Community Resources: Individual and CoupleLevel Analyses. Journal of Family Issues, 33(3), 316-340. Retrieved from http://journals.sagepub.com/doi/full/10.1177/0192513X11413877.

Instituto Brasileiro de Geografia e Estatística - IBGE. (2015). Trabalho. Recuperado de https://www.ibge.gov.br/estatisticas-novoportal/sociais/trabalho.html.

Johnson, S., Li, J., Kendall, G., Strazdins, L., \& Jacoby, P. (2013). Mother's and Father's Work Hours, Child Gender and Behavior in Middle Childhood. Journal of Marriage and Family, 75(1), 56-74. doi: 10.1111/j.1741-3737.2012.01030.x.

Kanji, S. (2013). Do Fathers Work fewer Paid Hours when their Female Partner Is the Main or an Equal Earner?. Work, employment and society, 27(2), 326-342. Retrieved from http://journals.sagepub.com/doi/full/10.1177/0950017012460321.

Kitterod, R. H., \& Rosen, M. (2016). Paternidade responsável na Noruega: quem são os "novos" pais?. In N. Fontoura \& C. Araújo. Uso do tempo e gênero (pp. 237-252). Rio de Janeiro: Uerj.

Landis, J. R., \& Koch, G. G. (1977). The Measurement of Observer Agreement for Categorical Data. Biometrics, 33(1), 159-174. Retrieved from https://www.dentalage.co.uk/wpcontent/uploads/2014/09/landis_jr__koch_gg_1977_kappa_and_observer_agreement.pdf 
Lozano, M., Hamaplová, D., \& Le Bourdais, C. (2016). Non-Standart Work Schedules, Gender, and Parental Stress. Demografic Research, 34(9), 259-284. doi: 10.4054/DemRes.2016.34.9.

Mahoney, A. R., \& Knudson-Martin, C. (2009). The Social Context of Gendered Power. In C. Knudson-Martin \& A. R. Mahoney (Eds.). Couples, Gender, and Power: Creating Change in Intimate Relationships. (pp. 17-29). New York: Springer.

Matias, M., \& Fontaine, A. M. (2012). A conciliação de papéis profissionais e familiares: o mecanismo psicológico de spillover. Psicologia:Teoria e Pesquisa, 28(2), 235-243. doi: $10.1590 /$ S0102-37722012000200012.

McGoldrick, M. (1995). As mulheres e o ciclo de vida familiar. In B. Carter \& M. McGoldrick (Orgs.). As mudanças no ciclo de vida familiar: uma estrutura para a terapia familiar (pp.7-29). Porto Alegre: Artes Médicas.

Meireles, E. (2016). Conciliação entre o trabalho e família. In E. Meireles (Org.). Trabalho, família e direito: estudos sobre família (pp.45-55). Curitiba: CRV.

Minotte, K. L. (2012). Family Structure, Gender, and the Work-Family Interface: Work-to-Family Conflict among Single and Partnered Parents. Journal of Family and Economics Issues, 33(1), 95-107. Retrieved from https://link.springer.com/article/10.1007/s10834-011$9261-4$.

Moser, L., \& Dal Pra, K. R. (2016). Os desafios de conciliar trabalho, família e cuidados: evidências do "familismo" nas políticas sociais brasileiras. Textos \& Contextos, 15(2), 382-392. doi: 10.15448/1677-9509.2016.2.21923.

Offer, S. (2014). Time with Children and Employed Parent's Emotional Well-Being. Social Science Research, 47, 192-203. doi: 10.1016/j.ssresearch.2014.05.003. 
Oliveira, L. B., Cavazotte, F. S. C. N., \& Paciello, R. R. (2013). Antecedentes e consequências dos conflitos entre trabalho e família. Revista de Administração Contemporânea, $17(4), 418-$ 437. Recuperado de http://www.scielo.br/pdf/rac/v17n4/a03v17n4.pdf.

Organização Internacional do Trabalho - OIT. (2009). Trabalho e família: rumo a novas formas de conciliação com corresponsabilidade social. Brasília: Secretaria Especial de Políticas para as Mulheres.

Roeters, A., \& Gracia, P. (2016). Child Care Time, Parents' Well-Being, and Gender: Evidence from the American Time Use Survey. Journal of Child and Family Studies, 25, 2469-2479. doi: $10.1007 /$ s 10826-016-0416-7.

Santos, S. M. C. B. (2016). Possibilidades e desafios do homem contemporâneo frente à conciliação entre trabalho e paternidade. In L. V. C. Moreira, E. P. Rabinovich \& P. C. S. V. Zucoloto. Paternidade na sociedade contemporânea (pp. 159-172). Curitiba: Juruá.

Silva, M. R., \& Piccinini, C. A. (2007). Sentimentos sobre a paternidade e o envolvimento paterno: um estudo qualitativo. Estudos de Psicologia, 24(4), 561-573. Recuperado de http://www.scielo.br/pdf/estpsi/v24n4/v24n4a15.pdf.

Souza, C. B. S., \& Moreira, L. V. C. (2016). Parentalidade, conjugalidade e trabalho: estratégias de conciliação na contemporaneidade. In E. Meireles (Org.). Trabalho, família e direito: estudos sobre família (pp. 45-55). Curitiba: CRV.

Taht, K., \& Mills, M. (2012). Nonstandard Work Schedules, Couple Desynchronization and Parent Child Interaction: a Mixed-Methods Analysis. Journal of Family Issues, 33(8), 1054-1087. Retrieved from http://journals.sagepub.com/doi/abs/10.1177/0192513X11424260. 
Família, gênero e jornada de trabalho

Walsh, F. (2016). Diversidade e complexidade nas famílias do século XXI. In F. Walsh. Processos normativos da família: diversidade e complexidade (4a ed., pp.3-27 ). Porto Alegre: Artmed.

Yavorsky, J. E., Dush, C. M. K., \& Schoppe-Sullivan, S. (2015). The Production of Inequality: the Gender Division of Labor across the Transition to Parenthood. Journal of Marriage and $\begin{array}{llll}\text { Family, } & 77(3), & 662-679 . & \text { Retrieved }\end{array}$ https://www.ncbi.nlm.nih.gov/pmc/articles/PMC4584401/.

Recebido em: 8/5/2018 